\title{
Responsiveness of Sweat Glands to Adrenaline in Skin Diseases. II
}

\author{
By \\ Yoshio Saito \\ (第藤 传 雄) \\ From the Department of Dermatology, Faculty of Medicine, \\ Tohoku University, Sendai; Director: Prof. $M$. It $\hat{o}$
}

(Received for publication, October 15, 1953)

Adrenaline sweating threshold (A. S. T.) values of 269 patients with skin diseases were examined in healthy and diseased skin area.

The method for testing adrenaline sweating was described in the proceeding section in this journal.

Results of experiment are as Table I.

\section{Comment}

1) Depigmented areas. The lesions of vitiligo showed prevalence of hypoexcitability, including some cases of negative excitability. This observation is of interest in collation with the vegetative nerve function noted in connection with the pathological mechanism of this disease. Disturbance of sewat secretion in depigmented areas has been pointed out by Burgess and Warner, Leschke, Ullmann, Leloir, Kaposi and McChabrier, while Takigawa ${ }^{1 /}$ has reported anomalous results in his adrenaline wheal tests on vitiligo. The tendency to decreased sweating excitability may be accepted as natural when we remember that Prof. Itô ${ }^{2)}$ of our Clinic has observed dilation of blood vessels in his histological study on such lesions. However, the areas affected by nevus systematicus depigmentosus never showed negative nor $10^{-4}$ and there was no difference in the excitability of the diseased and healthy parts in most cases. From these it can be admitted that there exists appreciable difference between these two diseases in sweating excitability. Recently Halter ${ }^{3}$ reported that the two diseases can be differenciated by the change of sweat secretion in response to heat; this is in good harmony with my observation. The cause of such a difference may be sought in the fact that whereas the vitiligo is post-natal and progressive, consequently involving various dermal functions, the nevus systematicus depigmentosus is in almost all cases limited in a certain area and has only to do with the function of melanin production without appreciably interfering with the sweating function. 
TABLE I

Adrenaline Sweating Threshold Values in Various Dermatological Lesions

Vitiligo

Depigmented areas

Nevus systemat. depigmentosus

Hyperpigmented areas

Nevus pigmentosus

Nevus systemat. pigmentosus

Nevus fuscocaeruleus ophthalmomaxillaris Ota

Xeroderma pigmentosum

Fixed drugexanthem

Depilated Areas

Alopecia areata

\section{Sensory anesthetic areas}

Lepra nervosa

Lepra maculosa

\section{Areas with vascular} disturbances

Hemangioma

Klippel-Weber's disease

Nevus anaemicus

Erythema exsudat. multiforme

Purpura

Perniosis

Type of erythema exsudativum

Type of cyanosis-swelling

Acrocyanosis

\section{Keratotic areas}

Ichthyosis vulgaris

Psoriasis

Trichophytosis

Darier's disease

Keratosis follicul. squamosa Dohi

\section{Lichenificated and}

eczematous areas

Neurodermitis circumscripta

Neurodermitis disseminata

Atopic dermatitis

Eczema chronicum

Contact dermatitis

Eczema seborrhoicurn

Atrophied skin areas

Sclerodermia diffusa

Sclerodermia en bandes

Poikilodermia

\begin{tabular}{|c|c|c|c|c|c|c|c|c|c|c|c|c|}
\hline \multirow[t]{2}{*}{ Cases } & \multicolumn{7}{|c|}{$\begin{array}{c}\text { Concentration of adrenaline in } \\
0.9 \% \text { saline solution }\end{array}$} & \multirow[b]{2}{*}{$\begin{array}{l}\text { Nega- } \\
\text { tive§ }\end{array}$} & \multicolumn{4}{|c|}{$\begin{array}{l}\text { Comparison of A.S.T. values } \\
\text { in the affected and normal } \\
\text { skin areas }\end{array}$} \\
\hline & $10^{-10}$ & $10^{-9}$ & $10^{-8}$ & $10^{-7}$ & $10^{-6}$ & $10^{-5}$ & $10^{-4}$ & & $\mathrm{~N}^{+}>\mathrm{A}^{*}$ & $\mathrm{~N}=\mathrm{A}$ & $\mathrm{N}<\mathrm{A}$ & $\begin{array}{c}\text { Both } \\
\text { negative }\end{array}$ \\
\hline 26 & & & & 6 & 5 & 6 & 5 & 4 & 16 & 9 & 1 & \\
\hline 7 & & & & 1 & 4 & 2 & & & 2 & 5 & & \\
\hline 16 & & & & & 1 & 3 & 6 & 6 & 12 & 3 & & 1 \\
\hline 10 & & & 1 & 2 & 5 & 2 & & & 5 & 2 & 3 & \\
\hline 8 & & & & 1 & & 1 & 4 & 2 & 8 & & & \\
\hline 2 & & & & 1 & & 1 & & & & 2 & & \\
\hline 1 & & & & 1 & & & & & & 1 & & \\
\hline 39 & & & & 2 & 8 & 5 & 12 & 12 & 34 & 4 & & 1 \\
\hline 24 & & & & & 1 & 1 & 1 & 21 & 10 & 2 & & 12 \\
\hline 8 & & & & & 1 & 3 & 1 & 3 & 4 & 3 & & 1 \\
\hline 9 & & & & 2 & 4 & 1 & 1 & 1 & 5 & 4 & & \\
\hline 4 & , & & & 1 & 1 & 2 & & & 1 & 3 & & \\
\hline 2 & & & & & 2 & & & & & 2 & & \\
\hline 13 & 1 & & & 4 & 2 & 3 & 2 & 1 & 3 & 9 & & 1 \\
\hline 3 & 1 & & & & 2 & & & & & 3 & & \\
\hline 3 & 1 & 1 & & & 1 & & & & 1 & 2 & & \\
\hline 3 & & & & & & & 1 & 2 & 3 & & & \\
\hline 1 & & 1 & & & & & & & & 1 & & \\
\hline 8 & & & 5 & 1 & 2 & & & & & 5 & 3 & \\
\hline 10 & & & & 1 & 2 & 1 & 2 & 4 & 8 & 2 & & \\
\hline 5 & & & & & & 1 & 3 & 1 & 4 & & & 1 \\
\hline 1 & & & & & & 1 & & & 1 & & & \\
\hline 1 & & & & & 1 & & & & & 1 & & \\
\hline 4 & & & & & 1 & 1 & & 2 & 4 & & & \\
\hline 22 & & & & 1 & 4 & 7 & 2 & 8 & 16 & 4 & & 2 \\
\hline 10 & & & & 1 & 2 & 4 & 1 & 2 & 6 & 3 & & 1 \\
\hline 9 & & & & & & & 3 & 6 & 8 & & & I \\
\hline 10 & & & & 1 & 2 & 1 & 1 & 5 & 8 & 1 & & 1 \\
\hline 2 & & & & & 1 & I & & & 2 & & & \\
\hline 3 & & & & 1 & 1 & & & 1 & 1 & 2 & & \\
\hline 2 & & & & 2 & & & & & & 1 & 1 & \\
\hline 1 & & & & & & & & 1 & 1 & & & \\
\hline
\end{tabular}

†, A. S. T. value in normal skin areas, *, A. S. T. value in affected skin areas, $\S$, No response to $10^{-4}$ in both areas. 
2) Hyperpigmented areas. In nevus pigmentosus cases, many showed A. S. T. of 10-4 and negativeness, though it must be born in mind that where the nevus was deep colored, the black sweat spots in testing the diseased area were sometimes rather difficult to distinguish. In nevus systematicus pigmentosus cases, however, the lesions were generally lighter in color and the sweat spots appeared more clearly defined, and no such cases of decreased excitability was ever found. On the contrary, some cases were found to show even increased excitability in the diseased than in the healthy skin. Such obesrvations seemed to show the closer relation to the vegetative nerves of the nevus systematicus pigmentosus, sometimes called the localized nerve nevi. The nevus fuscocaelureus opthhalmomaxillaris Ôta cases showed always decreased excitability in the diseased areas, in consonance with the results showing angioneurotic disturbance obtained by K. Yoshida' ${ }^{4}$ of our Clinic in histamine scratch tests, and with the histological observation that most prominent change of this disease lies in the corium.

3) Depilated areas. Very many cases of the areas affected by alopecia areata showed A. S. T. of $10^{-4}$ or negative, in most cases markedly higher than the unaffected areas. These results are deemed natural in consideration of the local disturbance of the vegetative nerve function and the histological observation of local atrophy of sweat glands by Tsukada ${ }^{5)}$ of our Clinic and the efficacy of acetylcholine in treating this disease.

4) Sensory anesthetic areas. Most of the areas of sensory anesthesia in leprosy patients showed negative response. However, in the maculae of lepra maculosa few cases of negativeness and equal A. S. T. value to the healthy skin areas were observed. These remind of the temporary hypersensitivity and paresthesia sometimes presented in lepra maculosa. Yoshimura $^{6}$ reported that the degeneration of sweating function in leprosy patients was not only due to the degenerative change of nerves, but also to the mechanical disturbances exerted by the leprous infiltration in the sweat glands and their surroundings. My findings are in harmony with such a proposition.

5) Areas with vascular disturbances. 5 cases of hemangioma showed higher A. S. T. than, and 4 cases equal to the healthy areas. One case of Klippel-Weber's disease showed higher A. S. T. than, and 3 cases equal to, the unaffected areas, but comparing the healthy part in affected extremities with the one in unaffected site, the decreased excitability in the former was shown suggestive of the disturbance of trophic nerves. All the nevus anaemicus and most of the erythema exsudativum and purpura cases showed the equal A. S. T. values in the diseased to the healthy areas.

Among the pernio cases, the erythema exsudativum multiforme type showed normal A. S. T. in two cases and hypoexcitability in one case in 
the affected sites, while the cyanosis-swelling type showed $10^{-4}$ or negative A. S. T. in all four cases. This difference in reaction by type is in consonance with Arai's ${ }^{7}$ report that at the skin temperature lower than $20^{\circ} \mathrm{C}$ when the peripheral blood vessels are paralized, no sweating could be induced by adrenaline administration.

6) Keratotic areas. Such areas in ichthyosis vulgaris mostly showed the A. S. T. of $10^{-8}$, manifesting a decided hyperexcitability and in no case the A. S. T. was higher in the diseased than in the healthy parts, a phenomenon rarely duplicated in other skin diseases. Prof. Itô ${ }^{81}$ has already pointed out that this disease has the disturbance of sweating function as one of its important causative factors, in consideration of the facts that it tends to be alleviated in summer when sweating is most plentiful and that pilocarpine injection showed therapeutic effects in some cases. My results above also endorse the Itô's observations about the disturbance in sweating function. In psoriasis cases, the A. S. T. value in the diseased parts showed a tendency to rise, in most cases to the extent of $10^{-4}$ and negativeness. Ichthyosis vulgaris and psoriasis are both known to prefer to attack the extensor surfaces of the extremities and it is worthy of special note that these two diseases are opposite in their response to adrenaline.

7) Lichenificated and eczematous areas. In neurodermitis circumscripta and disseminata, eczema chronicum, contact dermatitis and eczema seborrhoicum cases, the A. S. T. tended to rise in the diseased areas. We are reminded of the reports by Sulzberger'), Louis Tuft $^{10}$ et al. to the effect that, considering the stagnation of sweating due to the horny plugging of the opening of sweating pores in the diseased areas, disturbance of sweating is an important pathogenic factor of atopic dermatitis.

8) Atrophied skin areas. Two out of three cases of sclerodermia diffusa showed equal A. S. T. value to unaffected and the one case higher value than healthy areas, but sclerodermia en bandes showed no higher value in involved lesions. The one poikilodermia case showed higher A. $\mathrm{S}$. T. value in their diseased areas.

\section{ConcLusion}

The results of A. S. T. test in the affected areas in various dermatoses are as follows :

1. Depigmentation, Hyperpigmentation, alopecia, sensory anesthesia, lichenification, eczema and atrophy cases had decided hypoexcitability than in the healthy skin areas of the same subject.

2. Erythema exsudativum and purpura cases showed almost no difference in A. S. T. in both diseased and healthy skin areas.

3. The pernio cases especially cyanosis-swelling type showed hypoexcitability. 
4. Comparing the healthy part in affected extremities with that in unaffected site in Klippel-Weber's Disease patients, the decreased excitability in the former was shown suggestive of the disturbance of trophic nerves.

5. Ichthyosis vulgaris showed strong hyperexcitability in the diseased areas, moreover some cases presented lower A. S. T. values than in the healthy areas.

6. Psoriasis cases, on the contrary, showed a marked hypoexcitability.

\section{References}

1) Takigawa, Hifuka Seibyoka Zasshi (Jap. J. Dermat. \& Vener.), 1926, 30, 1001.

2) Itô, Tohoku J. Exp. Med., 1952, 55, Supplement, 72.

3) Halter, Dermat. Wschr., 1952, 125/1, 1.

4) Yoshida, Tohoku J. Exp. Med., 1952, 55, Supplement, 34.

5) Tsukada, Hifuka Seibyoka Zasshi (Jap. J. Dermat. \& Vener.), 1937, 41, 882.

6) Yoshimura, ibid., 1934, 35, 105.

7) Arai, Tohoku J. Exp. Med., unpublished.

8) Itô, ibid., 1950, 53, 85.

9. Sulzberger, et al., J. Invest. Dermat., 1947, 9, 221.

10) Tuft, et al., ibid., 1950, 15, 333. 